\title{
Strong leadership: the case for global connections
}

\section{Prof Elizabeth Rosser}

Professor of Nursing, Deputy Dean (Education), Bournemouth University

RN, RM, RNT, MN, Dip N Ed, Dip RM, DPhil, FHEA.

President of the Phi Mu Chapter (England)

\section{Assoc Prof Janet Scammell}

Professional lead for Adult and Children's and Young People's Nursing, Bournemouth

University

RGN, SCM, RNT, BSc, MSc, DNSci.

President Elect, Phi Mu Chapter

\section{Dr Ann Bevan}

Senior Lecturer and Programme Lead, Children's and Young People's Nursing,

Bournemouth University

RN, RSCN, PhD, FHEA

Board member and Treasurer, Phi Mu Chapter

\section{Prof Vanora A Hundley}

Professor of Midwifery, Centre for Midwifery, Maternal and Perinatal Health, Bournemouth University

BN, RGN, RN, RM, MSc, PhD, FHEA

Phi Mu Chapter

\section{Acknowledgements}

We are grateful to Eileen Richardson for distributing the email invitation and reminders to Chapter members.

\section{Correspondence to:}

Professor Elizabeth Rosser

Bournemouth University,

School of Health \& Social Care

Royal London House,

Christchurch Road,

Bournemouth,

BU1 3LT, UK.

\section{Email erosser@bournemouth.ac.uk}

Key words: survey, scholarship, networking, culture, leadership, collaboration, scholarship, global networking, quality care 


\begin{abstract}
Aims and Objectives: To identify how nurse leaders view and experience the opportunities offered by one of the largest global nursing organisations Sigma Theta Tau International (STTI).

Background: Worldwide, nursing leadership is challenged with addressing the complex issues impacting on care delivery. International nursing organisations are a means to bring together individuals to promote leadership and scholarship for nursing practice to promote patient safety and quality care. The newly established all-England Chapter of STTI is a recent addition to the society in terms of nurse leadership in Europe; and as such faces challenges as it establishes its identity and seeks to interpret the organisational vision: to advance world health through nursing leadership and scholarship. Moving forward, members views were sought on the goals of the chapter and how they may be enacted.

Design: In July 2013, all chapter members at that time had been nominated on the basis of achievement in nurse leadership; all were invited to participate in an online survey. The online questionnaire contained a series of closed and open questions.

Results: Most respondents joined because they believed in the vision and networking opportunities STTI provides. Three themes were extracted from the data: the value of networking and communication, leadership and the development of culturally sensitive organisations and the need for shared scholarship for nursing practice.

Conclusion: Findings indicate the growth of effective leadership at all levels of nursing could be harnessed through successful collaboration and keen support for robust connections between practice and education to promote quality care

Relevance to Clinical Practice: Whilst challenging, globalisation presents an opportunity for a nursing society such as STTI to work collaboratively to address health care issues. A nursing society which explores and resolves its own complex issues by actively promoting leadership and collaborative scholarship, reveals a potential to empower the profession to share our collective solutions towards enhancing clinical practice.
\end{abstract}


What does this paper contribute to the wider global clinical community?

- International organisations, such as STTI, are a means to bring together individuals to promote leadership and scholarship for nursing practice.

- Strong leadership is key to address the complex issues arising in nursing practice and

global collaboration can help support this.

- The society actively promotes strong leadership in order to collectively look for solutions to improve clinical practice. 
Strong leadership: the case for global connections.

Rosser E, Scammell J, Bevan A and Hundley VA, Journal of Clinical Nursing, 2016

\section{Introduction}

Nursing leadership has been under the spotlight in recent years in light of significant and high profile failures to the care of patients across the globe (Kirkup 2015, Wong, 2015, Berwick 2013, Cohen \& Ezer 2013, Francis 2013, Reader \& Gillespie 2013). More than ever professional nursing is facing significant and complex challenges, otherwise known as 'wicked' issues (Ferlie et al 2011). A number of these have the potential to seriously impact on nursing's goal of improving the health of the world's people. Popularised by a 1973 paper (Rittel and Weber), the term 'wicked problem' refers to issues that are so complex that there is no single correct approach to solving them. Such issues require careful consideration to take into account the multiple factors involved. For example, 'wicked' issues such as workforce shortages, competency development, increasing patient acuity, ongoing reduction of resources and poor quality of professional work life combine to have a much greater impact on patient care than the effect of each one in isolation (Aiken et al, 2013; Mannix et al, 2013; Gantz et al, 2012; Flynn \& McKeown, 2009; Gabrielle et al, 2008). Although not attributed to nurses alone, evidence from various reports, especially in the United Kingdom (UK), indicates that in combination these challenges can result in gross failure in the 'system' leading to unacceptable and in some situations, inhumane, patient care (Francis 2010, 2013; Parliamentary \& Health Service Ombudsman, 2012; Rudman et al, 2012; Wallin, 2009). Such failures often result from a complex pattern of factors. However, central to most of them is a need for strong leadership. Ham \& Hartley (2013) and Wong (2015) reinforce the pivotal role of the leader who connects individuals and teams to the vision and mission of the organisation and who creates working conditions that promote high quality care. At the same time, Ham \& Hartley reinforce that strong leadership is key to the practice of each individual, so the culture of the organisation affirms the value base that it promotes. Given there are common issues across the globe, we need to learn from each other to grow and strengthen clinical leadership (Jackson \& Watson 2009) and support change through 
Strong leadership: the case for global connections.

Rosser E, Scammell J, Bevan A and Hundley VA, Journal of Clinical Nursing, 2016

scholarship. In this paper we focus on leadership at all levels and the role of a global organisation in supporting leadership.

To assist our learning from each other across the globe a number of initiatives have strengthened international communications. These include an explosion in the availability of worldwide information and immediate access to a potential community through the worldwide web. However, there is a need to connect real individuals together to unite in their collaboration. Sigma Theta Tau International (STTI) with its 2020 vision of becoming intentionally global has the potential to achieve these connections. By forming strategic partnerships through the society nurses learn from each other with the aim of growing their leadership potential. Members forge formal links through the many activities organised by the society and through the informal networks between Chapters and Regions. However the reach of the Society external to the USA, where the majority of the membership is held (STTI 2016a), is limited. Given the implications of the globalisation of nursing (Tschudin and Davis, 2008) this paper seeks to identify the potential for nurses joining the society from outside the USA to feel empowered to share their collective challenges, and to grow strong leadership in their respective countries.

The Phi Mu Chapter (England), chartered in 2011 has joined a consortium of six chapters in the recently established European Region of STTI. The society offers two categories of membership highly achieving students or nurse leaders (STTI 2016b). However, whilst all members were invited to contribute, at the outset, the members of Phi Mu Chapter were predominantly nurse leaders, with students only being admitted subsequently. It is from the nurse leader category that contributing respondents in this study were drawn. This reflects the purpose of the Chapter which is to grow leadership and scholarship for nursing practice and actively develop the network of nurse leaders globally. In this way they can share their local challenges and learn from each other to empower them to lead. The relatively recent introduction of the chapter in England and the lack of clarity nationally about the value of 
Strong leadership: the case for global connections.

Rosser E, Scammell J, Bevan A and Hundley VA, Journal of Clinical Nursing, 2016

such an organisation made it timely to explore the views of the membership on the benefits of the society. This paper reports the findings from a survey of members.

\section{Methods}

In July 2013 all members (who at that time were all nurse leaders from education and practice) of the Chapter were invited to participate in the study by way of an email invitation. The email provided detailed information about the survey and contained a link to the online survey. Ethical approval for the survey was obtained from Bournemouth University's research ethics committee. Respondents were provided with information and asked to consent by clicking either 'agree to participate' or 'don't want to participate'. Participation was voluntary; members were reassured that they could withdraw at any time and that nonparticipation or withdrawal would not affect them in any way. Those who did not consent were directed away from the survey to a page thanking them for their time.

Data were collected in July 2013, using a semi-structured survey tool designed to mirror a STTI survey conducted with European Nurses in 2012 (Merrell et al 2011). The survey used an online format delivered through SurveyMonkey. It contained both open and closed questions relating to STTI and took approximately 15 minutes to complete. The topic of the questions focused on their reasons for joining the society, the value of the global organisation, awareness of STTI resources and opportunities, and chapter specific questions such as their priorities for the future direction and engagement. A total of 18 open questions covered topics such as 'What should be the top three priorities for the Phi Mu Chapter in the next FIVE years?'. To help protect confidentiality, the survey did not contain information that would personally identify respondents, such as names, email or IP addresses. Two reminder emails were sent to all members of the Chapter, because it was not possible to identify who had responded. All four researchers participated in the analysis. Quantitative data were analysed using descriptive statistics, whilst analysis of the open questions used a qualitative content analysis (Elo \& Kyngäs 2007) which involved coding data then categorising to form 
Strong leadership: the case for global connections.

Rosser E, Scammell J, Bevan A and Hundley VA, Journal of Clinical Nursing, 2016

sub themes before bringing the analyses together to form three distinct themes. Although the findings were drawn from both the quantitative and qualitative data together, much of the detail from individual participants arose from analysing the qualitative data, which shaped the nature of the three chosen themes.

\section{Results}

Responses were received from 31 of the 71 members (44\%). All respondents were established nurse leaders and educationalists, drawn from Higher Education Institutions across England. There were no members who went to the survey and then did not consent to participate. The three themes extracted from the data were: The value of networking and communication, leadership and the development of cultural sensitivity and identifying the need for shared scholarship. For the purposes of this paper, we will focus on the importance of strong and effective leadership, as this was a common thread throughout the results.

\section{The value of networking and communication}

Members were very clear that active engagement was important if the England Chapter of STTI was to be sustained (Table 1). A lively programme of events was identified as a key means of engaging members $(81 \%, n=25)$, as was effective communication $(77 \%, n=24)$. Respondents did recognise their responsibilities in becoming more involved in the chapter and the benefits this could bring, "I have enjoyed the camaraderie of the members to date and believe we have a sound basis on which to build a much larger chapter"(P19).

Given the diversity of the membership widely spread geographically across England, respondents were asked about alternative means of engaging with the chapter other than face to face meetings. Apart from engaging in a Twitter journal club where only $31 \%$ wished to participate, figure 1 illustrates that the majority were happy to take part in a virtual meeting for example using telephone $(57 \%, n=18)$ or video conferencing $(68 \%, n=21)$, Skype $(69 \%$, $n=21)$, or webinar $(59 \%, n=18)$. 
Strong leadership: the case for global connections.

Rosser E, Scammell J, Bevan A and Hundley VA, Journal of Clinical Nursing, 2016

Predictably most people preferred face-to-face contact particularly at the commencement of membership, "the personal contact is essential to start the connection, to me after having met people of the chapter in person it will be easier to stay connected and engage [electronically]" (P9).

The most useful aspect of membership was identified as meeting people in different areas of the profession and in particular meeting other nursing leaders. Regular scholarly presentations in different venues around the country were highly valued as they provided an, "opportunity to engage in topical areas of practice" (P19). However, it was identified though that the scholarly events and meetings needed to be marketed more effectively.

Looking forward, the members were asked what they would like the chapter to offer them in the future. There was a desire that the chapter could be in a position to influence the direction of nursing in England. For example one member advocated, "links to decision makers such as the chief nurse and other nursing bodies such as the International Council of Nurses" (P4). In addition members wanted "opportunities for collaborating on research, scholarship and enterprise activities....across the Atlantic and with chapters in Europe" (P19).

\section{Leadership and the development of cultural sensitivity}

When asked what their top three priorities for the Chapter for the next year, members identified that developing leadership was one of the most important priorities for "becoming an important voice nationally for nursing" (Q21). Throughout the qualitative responses, leadership was demonstrated as a clear thread, either to support the members' individual growth, or, through international collaborations, enhance the leadership of the profession (Table 2).

The majority of respondents referred to the potential global reach of the society and about the value of using the society to understand and influence nursing at an international level. One member stated, "we have a much greater potential to achieve this global community" 
Strong leadership: the case for global connections.

Rosser E, Scammell J, Bevan A and Hundley VA, Journal of Clinical Nursing, 2016

(P19) [through membership]. An additional strength was perceived to be that STTI is focused solely on nursing across the profession as opposed to many other societies that are more clinically or subject focused. A member highlighted, "If we don't celebrate and justify nursing as a profession we will lose it and we all become health care professionals with a specialist role" (P23).

In response to the question 'What does STTI offer that is different from other societies?' most $(81 \%, n=25)$ referred to the global reach of the society and opportunities for collaboration across the world. Others were impressed by its focus on scholarship and raising the profile of nursing. One respondent commented,

'On a global stage quite a lot, but within different countries the domination seems to be the USA with the other countries as an add-on. I am sure that is not the intention but everything from billing, research to the newsletter, is very focused on the USA.' (P6).

Members were asked how they felt they could shape the chapter and its development and whilst there were a few who were unsure how they could become involved, many were very enthusiastic about being active and spreading the word and encouraging others to join. Most respondents joined STTI because they believed in the mission $(71 \%, \mathrm{n}=22)$ and it offered them the opportunity to network with like-minded individuals (Table 2).

\section{The need for shared scholarship}

For respondents being in a position to promote nursing scholarship emerged as an important reason for joining and remaining a member. As one member wrote when asked what the society could do for nursing and nursing research in England, "fly the flag for scholarship in nursing.... be a group that brings together research, practice and education in terms of people and projects" (P22). Others agreed, "[provide] direction on scholarship help nurses to develop in research and in academic writing" (P33). The chapter can play: "a major role in the advancement of nursing scholarship" (P29). 
Strong leadership: the case for global connections.

Rosser E, Scammell J, Bevan A and Hundley VA, Journal of Clinical Nursing, 2016

Scholarship, according to members, included networking with others and developing relationships to work together to engage in research or other scholarly activities. Scholarly presentations are well attended and valued by members and non-members alike. It is pertinent however to note the perception that nurses commonly know little of "STTI [nor] understands what it is about" (P29), perhaps because an Honor Society is unusual in the UK and Europe.

Current members stated how they value the scholarship opportunities of the chapter, as one member highlighted when asked what does STTI offer that is different from other societies, "it is focused on NURSING. We have societies that focus on specialist aspects of nursing and they seem successful and useful...Nursing should have core international ideals and values that can be supported by a legitimate knowledge base" (P23).

\section{Discussion}

The survey achieved a $44 \%(n=31)$ response rate, which is acceptable for an anonymous survey without the use of incentives (Hager et al, 2003). Three main themes arose from the results of the survey. These relate to the main areas which members see as the value of being part of an international society which has local and national purpose and the challenges in making it fit for purpose. Each theme will be considered individually and will focus on leadership.

\section{Networking and communication to grow strong leadership}

The value of networking nationally and internationally across the membership was viewed as one of the greatest potential benefits of the society both for the profession and for individual members. As the results showed this is not without its challenges. Given the geographical spread of members (Phi Mu Chapter 2016), as is the case in the wider nursing profession, innovative solutions need to be found. Indeed, Wood (2011) acknowledges the benefits of networking, of collaboration, cohesion and integration of groups as key to the 
Strong leadership: the case for global connections.

Rosser E, Scammell J, Bevan A and Hundley VA, Journal of Clinical Nursing, 2016

growth of strong and effective leadership and the implementation of an evidence-based change process to encourage positive energy which will contribute to its success.

Membership of a society that offers development opportunities to support strong leadership on an international basis has the potential to build a culture of leadership within the profession (Peltzer et al, 2015, Wong, 2015, Hurley \& Hutchinson, 2013). It was seen as important to build this culture and recognise the 'value-added' that such a society could offer. It was recommended that the respondents should, assert the credibility of the society through establishing links with nurse leaders nationally. Given its commitment to promote leadership at all levels on a global scale, STTI is well placed to make an impact on professional nurses in practice, education and in research thus addressing to some extent the 'wicked problems' that challenge nursing today, across the globe. Indeed, the society's recent introduction of the Global Advisory Panel for the Future of Nursing (GAPFON) is testament to its commitment to unite nurse leaders worldwide in realising its vision of improving the health of the world's people and is making progress (Klopper \& Hill 2015).

The benefits of collegial relationships in nursing are well recognised (Padgett, 2013; Gibson, 2012, Wood, 2011). These benefits include enabling capacity building (Ogilvie et al, 2003), enhancing the quality of information and resources (Attwood \& Wellik, 2012), and increasing the efficacy of practice (Simmons \& Adachi, 2012). However there is a need to enable meaningful connections and the majority of the survey respondents valued the potential global reach of the society to strengthen the voice of nursing on the international stage and enhance their leadership potential. As the challenges facing nursing identified at the outset of this paper are increasingly recognised as global problems (Gantz et al, 2012), supporting global nursing leadership is one way of recognising the commonality of the issues as well as collectively seeking solutions.

The value of developing global nursing leadership through mentoring was recognised in 2013 by a group of global leaders and members of STTI (Buckner et al 2014). . Given the interest in networking from the membership in England, this unique example on the 
Strong leadership: the case for global connections.

Rosser E, Scammell J, Bevan A and Hundley VA, Journal of Clinical Nursing, 2016

global stage could be mirrored, with the reach of the membership extending across the country. The global nursing leadership development opportunity exploited the existing networks within the society to make real connections to grow and strengthen nurse leadership at all levels. As Ham \& Hartley $(2013$, p40) advocate, promoting "clear and visible leadership for quality in their organisations" is key to achieving "authentic leadership and a supportive organisational culture". A society such as STTI actively promoting opportunities to nurture talent from point of qualification and throughout the nurse's career can make a significant difference to creating and developing the next generation leaders to address some of the 'wicked issues' as identified at the outset of this paper. Findings from this survey suggest a need to harness the collective energy of the members. Given the creation of the new global nursing leadership mentoring programme (Buckner et al 2014) to reach out to those locally, nationally and internationally to make meaningful connections is an initiative that should be actively promoted. However whilst there are many such opportunities on offer from societies such as STTI (eg International Council of Nurses), successful collaboration and networking are dependent on meaningful and effective communication.

The majority of members in this study report joining STTI for the networking possibilities and were excited at the prospect of being a member of the society. However, whilst they valued the need for active engagement, preferring face-to-face contact particularly at the outset, the cost of funding such connections in both time and travel needs serious consideration if it is to be sustained. Using technology to engage the dispersed membership in quarterly meetings around the country may be one way of combining initial face-to-face contact with the wider membership 'meetings' at a distance. Additionally, hosting one celebratory meeting annually for all may be the best compromise. Unlike the International Council of Nurses (ICN) which is a federation of 130 national nursing associations from across the world, uniquely STTI attracts individual membership and thus connects individuals on the global stage. Nevertheless, at a national level it was the ICN $(2005, \mathrm{p} 4)$ 
Strong leadership: the case for global connections.

Rosser E, Scammell J, Bevan A and Hundley VA, Journal of Clinical Nursing, 2016

which recommended that to produce nurses equipped to lead in the $21^{\text {st }}$ century, they must "develop the skills and confidence that will earn the status required to influence health policy". Empowering nurses to achieve the skills of transformational leadership to increase their confidence and decision-making, Buckner et al (2014) recognise the importance of mentorship to support them to grow and influence. Whilst there are a number of papers supporting the benefits of different ways of communicating (Wong, 2015, Wood 2011, Ogilvie et al 2003, Washer 2002,) it is important to build a trusting relationship to encourage open and frank discussion as advocated by Wood (2011). This would facilitate the free and speedy dissemination of ideas, deepen the level of debate and offer time and opportunity to reflect on the issues.

\section{Leadership and the development of cultural sensitivity}

As a member of the European Union, UK Nursing has tended to look to Europe for its collegiality, given its common mandates and funding opportunities (WHO, 2009), the survey results suggest that the opportunity to look to the US and ultimately globally, seems a very positive prospect. This may also be further supported following the recent UK referendum to exit from the European Union (TUC 2016). However, engaging with nurses from across diverse regions of the world creates the need to ensure cultural sensitivity when communicating and identifying creative solutions to the challenges that individuals face in their working lives.

The results illustrate the desire to network with like-minded colleagues $(71 \%)$ both within Europe and the US. This was reinforced in many of the qualitative responses. Partnership with the USA was viewed by some as a more novel and somewhat attractive prospect for those in England particularly given shared language. The US Institute of Medicine's report (2011, p221) on the Future of Nursing advocates the need for strong leadership "from the bedside to the boardroom" and promotes active collaboration with other leaders in this endeavour. However from the qualitative responses from the English membership in this 
Strong leadership: the case for global connections.

Rosser E, Scammell J, Bevan A and Hundley VA, Journal of Clinical Nursing, 2016

survey and considering their regular e-communication from Society members, STTI is perceived to be somewhat US-centric. This is perhaps reinforced by the fact that the STTI 'brand' and the concept of an Honor Society is unfamiliar to most UK nurses. However, members need to consider that the majority of the membership is based in the USA (STTI 2016). STTI is well used to collaborating and communicating online; however entering discussion forums where custom and practice are distinctly different is challenging and can be disconcerting, especially for the new member. It is beholden on us all to ensure communications are culturally sensitive.

Nevertheless, whilst the importance of effective communication has already been acknowledged, it is a culturally mediated phenomenon (Cioffi, 2003) and therefore imbued with challenges when working internationally. Clearly this is a test for any organisation, but as STTI has been long established in the USA, understandably it will have a time-honoured organisational culture with embedded processes. As one participant indicated, there seems no intention to exclude, however, some of the processes were perceived to have that effect. Indeed, evidence from nursing practice highlights how nurse migrants for example have experienced differing perceptions of the nurse's role (Buchan et al, 2003), differing experiences of team working (Hendel and Kagan, 2012) and differing working and economic conditions as well as regulations impacting on collaborative plans for nurse education (Hong, 2004: p191). Similarly, while members of STTI share the title 'nurse', the meanings we attribute to this word and related concepts do differ internationally. Although Buckner et al (2014) acknowledged a shared experience of leadership characteristics in the STTI global nursing leadership mentoring programme, Mannix et al (2013) acknowledge the role of good communication in the achievement of healthy workplaces of which leadership provides an important component. Sharing our collective experiences through international collaboration in a culturally sensitive environment has the potential to help us understand the problems of ineffective clinical leadership and support each other as agents of change to improve the environment for those giving and receiving professional care. 
Strong leadership: the case for global connections.

Rosser E, Scammell J, Bevan A and Hundley VA, Journal of Clinical Nursing, 2016

One of the advantages of STTI is its international membership and therefore the ability to affect change at a global level. Parmelli et al, (2011: 2) in a systematic review of strategies to change organisational culture to improve healthcare, state that organisational culture 'refers to the shared characteristics among people within the same organisation. These characteristics may include: beliefs, values, norms of behaviour, routines, traditions, and sense-making.' The question therefore arises as to whether members of STTI are similar enough to facilitate such sharing. The seminal research of Hofstede (2005) showed that cultural differences between nations are particularly found at the level of values, whereas cultural differences between organisations are especially identified the level of practices. This is alluded to in the survey in the comment that STTI needed a better understanding of nurse education and practice in the UK; whilst as nurses we share the same basic values; practices are likely to differ given the differing role and scope of nursing around the globe.

\section{The need for shared scholarship}

From a US perspective, Pilon et al (2014, p81) inform us that nurse leaders oversee the work of over 3 million registered nurses, a large number of licensed practical nurses and assistants and as such have considerable influence on "patient safety, quality and financial outcomes". They suggest the need for nurse leaders to be educated beyond degree level to continue to advance patient safety and quality care and therefore the opportunity to engage in collaborative scholarship. This opportunity of shared scholarship gives nurses the chance to discuss and debate the current available evidence and make an impact on clinical practice. A society which presents the opportunity through collaboration, for nurse leaders to explore and resolve the profession's own 'wicked' issues of competence development, rising patient acuity and workforce shortages by actively promoting leadership (Wong 2015) and collaborative scholarship empowers the profession to share our collective solutions towards radical change. 
Strong leadership: the case for global connections.

Rosser E, Scammell J, Bevan A and Hundley VA, Journal of Clinical Nursing, 2016

As a society, STTI defines clinical scholarship as "an approach that enables evidence-based nursing and the development of best practice to meet the needs of clients efficiently and effectively" (STTI, 1999, p 4). More recently, Hulsey et al (2014) from STTI remind us of the contribution of Boyer $(1990,1996)$ and the interconnected functions of scholarship including research, teaching, interdisciplinary debate, application and laterally the scholarship of engagement. Hulsey et al (2014) present STTI's position in recognising the importance of Boyer's work in advancing global health. They acknowledge that relevant nursing scholarship arises from all types of settings and embraces a wide range and type of evidence. From this study, promoting nursing and nurse scholarship emerged as important to chapter members, with some arguing for "scholarship" to be included in the chapter title in order to give a sense of what the chapter is about. Opportunities for collaborating on research projects are enabled through membership, networking at scholarly events and regular chapter meetings. However, the results indicate that members want greater scholarship connections with other chapters in Europe and other collaborative scholarly activities outside of research. Unlike established chapters in the US, there are currently few members from practice in the all-England chapter. However, results concur with previous research suggesting that greater inclusivity of clinical leaders should be explored to reflect the need to link scholarship with the practice of nursing (Thoun, 2009; Riley et al, 2002) and make a difference to patient care. Wilkes et al (2013) suggest that a shared understanding of scholarship between academics and practice appears to be elusive as many clinical nurses believe that scholarship is limited to academics.

Survey respondents also highlighted the importance of encouraging collaborations with students and newly qualified nurses in order to grow future scholars and widen the society's profile. These novice practitioners recently engaged in their own scholarship, present an "untapped resource" (P8) with the potential for the Chapter to provide a useful support through scholarly mentorship and develop the foundation for thought leadership. 
Strong leadership: the case for global connections.

Rosser E, Scammell J, Bevan A and Hundley VA, Journal of Clinical Nursing, 2016

It is evident from survey respondents that engagement with the scholarly events provided regularly by the chapter is valued and needed. It was acknowledged that the Phi Mu chapter can fill a niche in focusing solely on scholarship for all fields of nursing. Other societies such as the Royal College of Nursing in the UK have additional legal and Trade (Labor) Union functions and other membership groups focus on their own specific area of nursing. Goodman (2013) calls for the prioritisation of scholarly inquiry in nursing where contrary views and ideas are welcomed and debated. Indeed, scholarly seminars and presentations open to all nurses and students that foster the airing of ideas, should be encouraged and welcomed (Thompson \&Clark, 2013).

\section{Strengths and Limitations}

The main strength of this study is that it targeted the whole membership population of the allEngland chapter of STTI. Whilst a well established organisation in North America, its potential when transferred to Europe had not been explored. This survey explores this potential and the unique challenges that working in a different environment raises. However, we recognise the limitation of a $44 \%$ response rate and recommend caution when considering the results. Nevertheless, whilst we acknowledge that a low response rate from an online survey without incentives is common, Gerrish et al 2010 acknowledge the lack of representativeness of such a response rates where the opinion of those who fail to respond may offer a different opinion from those who do. Additionally, whilst the use of questionnaires is relatively quick and cheap to capture a large number of respondents, the format of the online questionnaires has particular advantages. The open-ended questions are already typed and do not require transcription and the closed-ended questions can be imported into statistical analysis software and so reducing errors in data entry. Whilst we acknowledge that the use of questionnaires as a tool have their pitfalls, Lo-Biondo-Wood and Haber (2014) recognise the increased efficiency and accuracy of the on-line surveys make it attractive. 
Strong leadership: the case for global connections.

Rosser E, Scammell J, Bevan A and Hundley VA, Journal of Clinical Nursing, 2016

\section{Conclusion and Implications for Nursing Practice}

This survey of the all-England Chapter of STTI found overall support for the mission of the society which focuses on leadership and scholarship for nursing practice.

Respondents valued the opportunity for collaborative scholarship, networking and communication as well as the need to be culturally sensitive to its membership. Through promoting the wider scholarship agenda through celebrating existing work as well as through promoting joint working, respondents advocated the society forging stronger links between education and practice to strengthen nurse leadership for quality care. In spite of the global information explosion through the worldwide web, the Chapter offers the opportunity to connect real individuals, other nurse leaders from across the country to unite in their collaboration. Networking and communication with like-minded colleagues nationally and internationally was viewed as the society's unique selling point in fostering strong leadership at all levels and many wished to become more active to ensure its sustainability. However, there remain challenges to the wider society in successfully embracing the vision of becoming 'intentionally global'. Given the complex and significant challenges facing nursing to improve the health of the world's people, members of this new chapter are intrigued to be involved in the society to understand and potentially influence nursing at an international level. However, they recognised the need for an organisation, well established in the US, to more fully understand the challenges facing the profession external to the US. Members seemed eager, through the opportunity for collaboration to support the wider society of STTI in becoming more culturally sensitive. A society which has the potential to unite the profession around the world through connectivity, collaborative scholarship and leadership development, offers the potential to create solutions to unite in addressing the catastrophic failures in care and is welcome. We must each embrace its vision and use the society to help us to make a difference to nursing practices and ultimately to improve people' lives and the health of the world's people.

5013 words 


\section{References}

Aiken LH, et al. (2013) Nurses' reports of working conditions and hospital quality of care in 12 countries in Europe. International Journal of Nursing Studies, 50, 143-153.

Attwood CA \& Wellik KE (2012) Collaboration, Collegiality and Cooperation:

Consumer Health Library Services and the American Cancer Society Navigator Role. Clinical Journal of Oncology Nursing, 16(5), 487-490.

Berwick D (2013) A Promise to learn, a commitment to act. Improving the safety of patients in England. London, National Advisory Group on the Safety of Patients in England. August.

Boyer E (1990) Scholarship reconsidered: The priorities of the professoriate. Princeton NJ. Carnegie Foundation for the Advancement of Teaching.

Boyer E (1996) The scholarship of engagement. Journal of Public Service and Outreach 1(1): 11-20.

Buchan J, Parkin T \& Sochalski J (2003) International Nurse Mobility: Trends and Policy Implications. Geneva" World health Organisation.

Buckner EB, Anderson DJ, Garzon N, Hafsteinsdottir TB, Lai CKY \& Roshan R (2014) Perspectives on global nursing leadership: international experiences from the field. International Nursing Review 61, 463-471.

Cioffi J (2003) Communicating with culturally and linguistically diverse patients in an acute care setting: nurses experiences. International Journal of Nursing Studies 40(3), 299-306

Cohen J \& Ezer T (2013) Human rights in patient care: A theoretical and practical framework. Health and Human Rights Journal 15(2), Accessed at:

http://www.hhrjournal.org/2013/12/human-rights-in-patient-care-a-theoretical-and-practicalframework/ on 29.1.16

Elo S \& Kyngäs H (2007) The qualitative content analysis process. Journal of Advanced 
Strong leadership: the case for global connections.

Rosser E, Scammell J, Bevan A and Hundley VA, Journal of Clinical Nursing, 2016

Nursing 62(1), 107-115. Accessed on 12.7.16 at

https://www.researchgate.net/profile/Satu Elo/publication/5499399 The qualitative content

analysis/links/02bfe5112a36ee6e8a000000.pdf

Ferlie E, Fitzgerald L, McGivern, G, Dopson S \& Bennett C (2011) Public policy

networks and 'wicked problems': a nascentsolution? Public Administration 89, 2:307-324

Flynn M \& McKewn M (2009). Nurse staffing levels revisited: A consideration of key

Issues in nurse staffing levels and skill mix research. Journal of Nursing Management 17(6), $759-766$

Francis R (2013) Report of the Mid-Staffordshire NHS Foundation Trust Public Inquiry.

The Stationery Office, London.

Francis R (2010) The Mid-Staffordshire NHS Foundation Trust Public Inquiry. 24

February, The Stationery Office, London. ISBN 978-0-10-296439-4

Gabrielle S, Jackson D \& Mannix J. (2008) Older women nurses: Health, ageing

concerns and Self-care strategies. Journal of Advanced Nursing 61(3), 316-325.

Gantz NR et al. (2012) Global nurse leader perspectives on health systems and workforce challenges. Journal of Nursing Management 20, 433-443.

Gerrish L \& Lacey A (2010) (editors) The Research Process in Nursing (6 $6^{\text {th }}$ Edition). WileyBlackwell, Chichester, England.

Gibson F (2012) Value of interaction. Nursing Children and Young People 24(7), 13.

Goodman B (2013) "What are nurse academics for?" Intellectual craftsmanship in an age of instrumentalism. Nurse Education Today 33, 87-89.

Hager MA, Wilson S, Pollak TH, \& Rooney PM (2003) Response Rates for Mail

Surveys of Nonprofit Organizations: A Review and Empirical Test. Nonprofit and

Voluntary Sector Quarterly 2003 32: 252-267.

Ham C \& Hartley N (2013) Patient-centred leadership: Rediscovering our purpose. The King's Fund, London.

Hendel T \& Kagan I (2012) Organisational values and organisational commitment: do 
Strong leadership: the case for global connections.

Rosser E, Scammell J, Bevan A and Hundley VA, Journal of Clinical Nursing, 2016

nurses' entho-cultural differences matter? Journal of Nursing Management, published on- line Dec 2012. DOI:10.111/jonm.12010

Hofstede G (2005) Cultures and organizations: software of the mind. New York; London:

McGraw-Hill.

Hong O (2004) Exploring the world through international occupational health programmes.

AAOHN Journal 52(5), 191-192.

Hulsey T, Nagelsmith L, \& Sharts-Hopko NC. (2014) STTI Scholarship Defined. The Virginia

Henderso Global Nursing e-Repository. Accessed on 24.6.16 at:

http://www.nursinglibrary.org/vhl/bitstream/10755/344731/1/ScholarshipDefined final.pdf

Hurley J \& Hutchinson M (2013) Setting a course: a critical review of the literature on

Nurse leadership in Australia. Contemporary Nurse 43(2), 178-182.

Institute of Medicine (2011) The Future of Nursing: Leading Change, Advancing Health.

Institute of Medicine October 5. Accessed on 14.7.16 at

http://www.nap.edu/read/12956/chapter/10\#p2001cde19980221

International Council of Nurses (2005) Guidelines on shaping effective health policy.

International Council of Nurses, Geneva. Accessed on 14.7.16 at http://www.nursing-

informatics.com/N4111/Guideslines shaping.pdf

Jackson D \& Watson R (2009) Editorial: Lead us not. Journal of Clinical Nursing 18(14), 1961-2.

Klopper HC, \& Hill M. (2015) Global Advisory Panel on the Future of Nursing (GAPFON) and

Global Health. [Global Commentary] Journal of Nursing Scholarship 47(1), 3-4.

Kirkup B (2015) The Report of the Morecambe Bay Investigation. Accessed on 1.5.16 at

https://www.gov.uk/government/uploads/system/uploads/attachment data/file/408480/47487

MBI Accessible v0.1.pdf

Lo-Biondo-Wood G \& Haber J (2014) Nursing Research: Methods and Critical Appraisal for

Evidence-Based Practice. ( $8^{\text {th }}$ edition) Elsevier, Mosby, St. Louis.

Mannix J, Wilkes L \& Daly J (2013) Attributes of clinical leadership in contemporary 
Strong leadership: the case for global connections.

Rosser E, Scammell J, Bevan A and Hundley VA, Journal of Clinical Nursing, 2016

nursing: an integrative review. Contemporary Nurse 45(1), 10-21.

Merrell J et al. (2011) What do European nurses want from STTI? A survey of active and inactive members in Europe. Presentation at the $41^{\text {st }}$ Biennium of Sigma Theta Tau International, Indianapolis, October.

Ogilvie L, Allen M, Laryea J \& Opare M (2003) Building capacity through a collaborative international nursing project. Journal of Nursing Scholarship 35(2) 113-118.

Padgett SM (2013) Professional collegiality and peer monitoring among nursing staff: An ethnographic study. International Journal of Nursing Studies. 50, 1407-1415.

Parliamentary and Health Service Ombudsman (2012). Improving care for older people. Moving Forward, annual report 2011-12. 10 $0^{\text {th }}$ July, accessed at http://www.ombudsman.org.uk/ data/assets/pdf file/0011/16022/PHSOannual report2012highres.pdf

Parmelli E, et al. (2011) The effectiveness of strategies to change organisational culture to improve healthcare performance. Cochrane Database of Systematic Reviews (2011). Issue 1. Art. No.: CD008315. DOI: 10.1002/14651858.CD008315.pub2.

Peltzer JN, Ford DJ, Shen Q, Fischgrund A, Teel CS, Pierce J, Jamison M \& Waldo T (2015) Exploring leadership roles, goals, and barriers among Kansas registered nurses: A descriptive cross-sectional study. Nursing Outlook 63, 117-123.

Phi Mu Chapter (2016) Sigma Theta Tau International, Phi Mu Chapter. Accessed on 12.7.16 at: http://phimu.nursingsociety.org/chaptermembers/chaptermembers

Pilon B, Crutcher TD, Leming-Lee S, Watters R, Wolgasts K \& Arnow D (2014) The Value Proposition for Graduate Education of Emerging Nurse Leaders: Immediate Benefit to Organizations. Nurse Leader June, pp81-85.

Riley JM, Beal J, Levi P, \& McCausland MP (2002) Revisioning nursing scholarship. Journal of Nursing Scholarship 34 (4), 383-389.

Reader TW \& Gillepie A (2013) Patient neglect in healthcare institutions: a systematic 
Strong leadership: the case for global connections.

Rosser E, Scammell J, Bevan A and Hundley VA, Journal of Clinical Nursing, 2016

review and conceptual model. BMC Health Services Research 13:156. Accessed at:

http://bmchealthservres.biomedcentral.com/articles/10.1186/1472-6963-13-156 on 29.1.16

Rittel HWJ \& Webber MM (1973) Dilemmas in a General Theory of Planning. Policy

Sciences 4, 155-169. Accessed on 12.7.16 at

http://www.uctc.net/mwebber/Rittel+Webber+Dilemmas+General Theory of Planning.pdf

Rudman A, Gustavson P, Ehrenberg A, Boström AM \& Wallin L (2012) Registered nurses'

evidence-based practice: A longitudinal study of the first five years after graduation.

International Journal of Nursing Studies 49, 1494-1504.

Sigma Theta Tau International (2016a) Chapter Directory. Accessed on 1.7.16 at:

http://chapterdirectory.nursingsociety.org/\#/

Sigma Theta Tau International (2016b) Nurse Leader membership criteria. Accessed on

31.7.16 at http://www.nursingsociety.org/why-stti/stti-membership/apply-now/nurseleader-membership-criteria

Sigma Theta Tau International, Clinical Scholarship Task Force (1999) Clinical scholarship resource paper: Knowledge work, in service of care, based on evidence. Available:

http://www.nursingsociety.org/aboutus/PositionPapers/Documents/clinical

scholarship paper.pdf accessed $15^{\text {th }}$ January 2014

Simmons K \& Adachi K (2012) Global Collaboration in Disaster Nursing. AORN Journal, 96(2), 196-202.

Thompson DR, \& Clark AM (2013) Academic culture in nursing: devalued, defiant or dead? International Journal of Nursing Studies 50, 1431-1433.

Thoun DS (2009) Toward an appreciation of nursing scholarship: recognizing our

traditions, contributions, and presence. Journal of Nursing Education 48, (10), 552-556.

Trade Union Centre [TUC] (2016) The NHS, how Brexit could affect our health service.

Trade Union Centre. Accessed on 1.7.16 at

https://www.tuc.org.uk/sites/default/files/brexit-TheNHS2.pdf

Tschudin V \& Davis A The Globalisation of Nursing. Oxford: Radcliffe 
Strong leadership: the case for global connections.

Rosser E, Scammell J, Bevan A and Hundley VA, Journal of Clinical Nursing, 2016

Wallin L (2009) Knowledge translation and implementation research in nursing. International Journal of Nursing Studies 46(4), 576-587.

Washer P (2002) Professional networking using computer-mediated communication. British Journal of Nursing 11(18), 1215-1218.

Wilkes L, Mannix J, \& Jackson D (2013) Practicing nurses perspective of clinical scholarship: a qualitative study. BMC Nursing 12, 21.

Wong C (2015) (Editorial) Connecting nursing leadership and patient outcomes: state of the science. Journal of Nursing Management 23, 275-278.

Wood K (2011) Group leadership during the change process. Ky Nurse 59(3), 5-6.

Accessed at www.ncbi.nlm.nih.gov/pubmed/21848018

World Health Organisation (2009) (second edition) European Union Standards for Nursing and Midwifery: Information for Accession Countries. World Health Organisation Regional Office for Europe. Accessed on 14.2.14 at http://www.euro.who.int/ data/assets/pdf file/0005/102200/E92852.pdf 
Table 1. Engaging with membership

\begin{tabular}{|l|c|}
\hline What, in your opinion, helps sustain the Chapter or Honor Society? \\
- Effective communication across the membership and with others in the Region \\
$\quad$ and internationally. & n (\%) \\
- Lively programme of events set up well in advance and posted on the website. & $25(77)$ \\
- Offering joint events with other nursing groups and societies & $15(48)$ \\
$\quad$ overload of a few individuals & $20(65)$ \\
$\quad$ Spreading the word about STTI in clinical practice and across the student & $18(58)$ \\
\hline community. & $26(90)$ \\
Hese you attended a meeting or event run by the Phi Mu Chapter? & $3(10)$ \\
No & $9(35)$ \\
\hline If yes, how useful did you find the meeting? & $11(42)$ \\
Extremely useful & $6(23)$ \\
Very useful & 0 \\
Moderately useful & 0 \\
Slightly useful & \\
\hline Not at all useful & $4(80)$ \\
\hline If not attended a meeting, would you like to? & $1(20)$ \\
\hline Yes & \\
No & \\
\hline
\end{tabular}


Strong leadership: the case for global connections.

Rosser E, Scammell J, Bevan A and Hundley VA, Journal of Clinical Nursing, 2016

Table 2. Membership of Sigma Theta Tau International

\begin{tabular}{|l|c|}
\hline What are the reasons you joined STTI? & $\mathrm{n}(\%)$ \\
To enhance the profile of nursing and support the membership through leadership, & $22(71)$ \\
scholarship, education and research (STTI mission). & $22(71)$ \\
$\begin{array}{l}\text { Having the opportunity to network with likeminded colleagues, nationally and } \\
\text { globally }\end{array}$ & $12(39)$ \\
A belief in the organization and a recognition of the benefits of collaborating \\
internationally. \\
To enhance the visibility, development and standard of nursing scholarship locally, \\
nationally and internationally & $17(55)$ \\
Access to research funding & $5(16)$ \\
Enhance my CV or resume & $10(31)$ \\
Other [academic prize (3), promote collaboration (3), raise profile university (2)] & $8(26)$ \\
\hline Proportion of participants that knew about STTI resources: & \\
Journal of Nursing Scholarship & $29(94)$ \\
Community & $18(60)$ \\
The Circle & $14(47)$ \\
Leadership Institute & $15(50)$ \\
Research Library & $22(71)$ \\
Chapter Information on STTI web site & $23(77)$ \\
\hline Do you feel you get value for the money you pay for STTI membership? & \\
Yes & $8(26)$ \\
No & $8(26)$ \\
Unsure & $15(48)$ \\
\hline
\end{tabular}


Strong leadership: the case for global connections.

Rosser E, Scammell J, Bevan A and Hundley VA, Journal of Clinical Nursing, 2016

Figure 1. Would you participate in a virtual meeting or event?

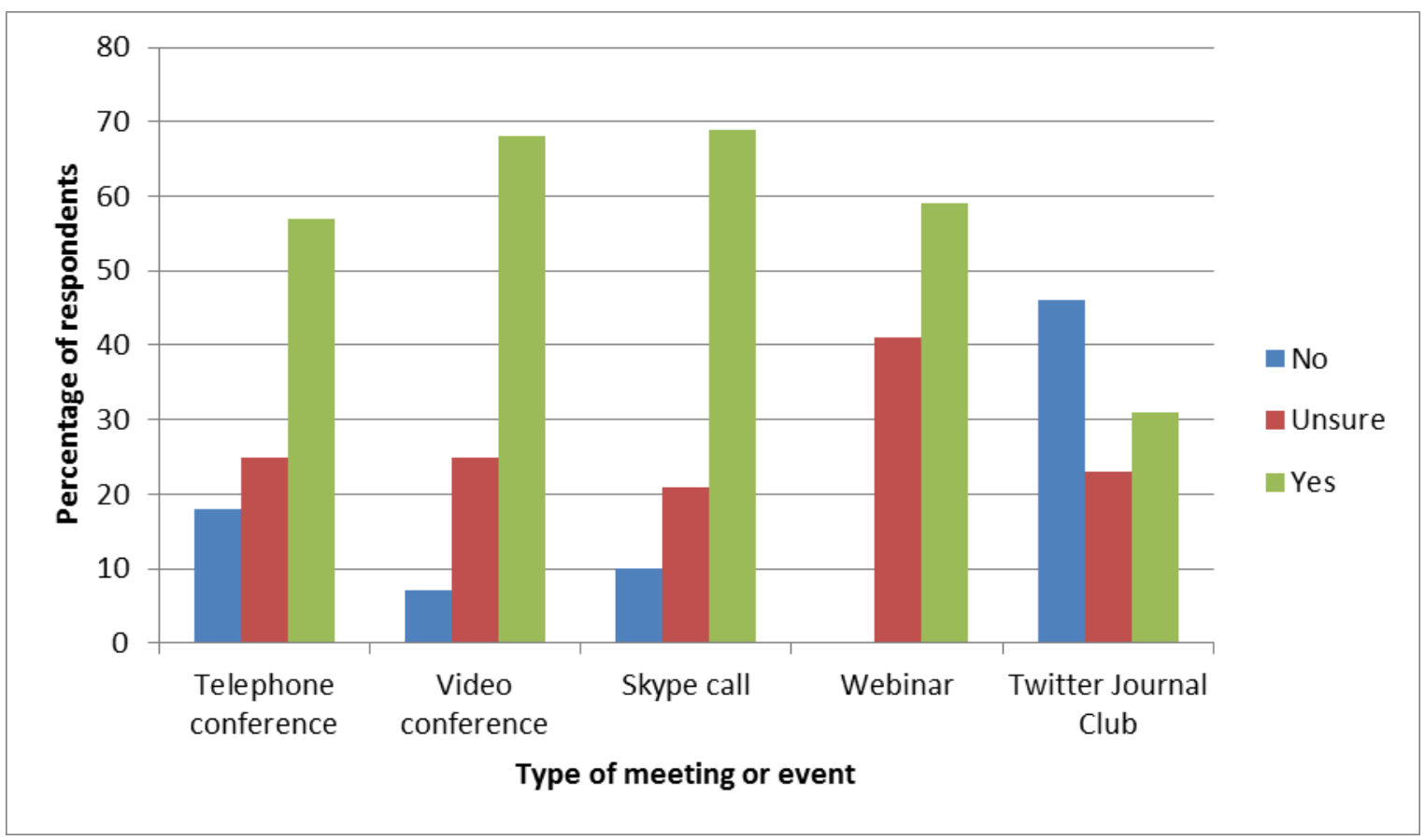




\section{Appendix 1. Survey tool}

The survey tool was a semi-structured online survey. The quantitative questions were based on a STTI survey conducted with European Nurses in 2012 (Merrell et al 2011).

\begin{tabular}{|c|c|}
\hline 1. & $\begin{array}{l}\text { Consent: } \\
\text { Clicking on the "agree" button below indicates that: - you have read the above } \\
\text { information - you voluntarily agree to participate - you are a member of STTI Phi Mu } \\
\text { Chapter If you do not wish to participate in the research study, please decline } \\
\text { participation by clicking on the "disagree" button }\end{array}$ \\
\hline 2. & $\begin{array}{l}\text { What are the reasons you joined STTI? (Please tick all those that apply) } \\
\text { - To enhance the profile of nursing and support the membership through leadership, } \\
\text { - } \text { scholarship, education and research (STTI mission). } \\
\text { - A belief in the organization and a recognition of the benefits of collaborating } \\
\text { internationally. } \\
\text { - To enhance the visibility, development and standard of nursing scholarship locally, } \\
\text { nationally and internationally. } \\
\text { - } \text { Access to research funding } \\
\text { - } \text { Onhance my CV or resume } \\
\text { Other (please specify) }\end{array}$ \\
\hline 3. & $\begin{array}{l}\text { What, in your opinion, helps sustain the Chapter or Honor Society? } \\
\text { - Effective communication (for e.g. newsletter, Facebook, Skype) across the membership } \\
\text { and with others in the Region and internationally. } \\
\text { - Lively programme of events set up well in advance and posted on the chapter/honor } \\
\text { society website. } \\
\text { - Offering joint events with other nursing groups and societies } \\
\text { - Actively engaging the membership in activities - sharing the load and avoiding overload } \\
\text { of a few individuals. } \\
\text { - Spreading the word about STTI in clinical practice and across the student community. } \\
\text { - Other (please specify) }\end{array}$ \\
\hline 4 & $\begin{array}{l}\text { Do you feel you get value for the money you pay for STTI membership? } \\
\text { - Yes } \\
\text { - No } \\
\text { - Unsure }\end{array}$ \\
\hline 5. & If yes, please tell us why. \\
\hline 6 & If no, please tell us why. \\
\hline 7 & $\begin{array}{l}\text { How useful do you find the following resources: } \\
\text { - Journal of Nursing Scholarship } \\
\text { - Community } \\
\text { - The Circle } \\
\text { - } \quad \text { Leadership Institute } \\
\text { - } \quad \text { Research Library } \\
\text { - } \quad \text { Chapter information on STTI web site } \\
\end{array}$ \\
\hline 8. & $\begin{array}{l}\text { Have you completed a volunteer interest profile at headquarters? } \\
\text { - Yes } \\
\text { - No } \\
\text { - Don't know }\end{array}$ \\
\hline 9 & What does STTI offer that is different from other societies? \\
\hline 10. & $\begin{array}{l}\text { Have you attended a meeting or event run by the Phi Mu Chapter? } \\
\text { - Yes } \\
\text { - No }\end{array}$ \\
\hline 11 & If yes, how useful did you find it? \\
\hline
\end{tabular}




\begin{tabular}{|l|l|}
\hline & $\begin{array}{l}\text { - } \text { Extremely useful } \\
\text { - Very useful }\end{array}$ \\
& - Moderately useful \\
- Slightly useful
\end{tabular}

